\title{
The Effect of Micronutrient Intake on Cognitive Function and Physical Activity of the Elderly
}

\author{
Abbas Akbari ${ }^{1,{ }^{*}}$, Fatemeh Mirakhori ${ }^{1}$, Mahdi Ashouri ${ }^{1}$ and Sadaf Nehzat Norozi Tehrani ${ }^{1}$ \\ ${ }^{1}$ Imam Khomeini International University, Qavin, Iran \\ Corresponding author: Imam Khomeini International University, Qavin, Iran. Email: abbasakbary98@gmail.com
}

Received 2021 November 22; Accepted 2021 December 24.

\begin{abstract}
Objectives: The purpose of this research was to investigate the effect of micronutrient intake on cognitive function and physical activity of the elderly.

Methods: The subjects included all elderly people over 60 years of age in Robat Karim city in 2018. 90 elderly males participated voluntarily in the research after signing the informed consent form. The short form of Beck questionnaire of physical activity and MMSE test were respectively used to measure the levels of physical activity and cognitive status of participants. Pearson correlation test was used to analyze the data.

Results: The results indicated that there was a significant relationship between each of the micronutrients and cognitive performance of the elderly $(\mathrm{P} \leq 0.05)$. Additionally, there was a significant relationship between each of the micronutrients with the level of physical activity of the elderly $(\mathrm{P} \leq 0.05)$.

Conclusions: Conclusively, micronutrients intake could be of much importance for cognitive function and physical activity of the elderly.
\end{abstract}

Keywords: Micronutrients, Cognitive Function, Physical Activity, Elderly

\section{Background}

The elderly population often suffers from malnutrition due to aging, physiological changes and lifestyle changes. the aging process is associated with a number of physiological, economic and social factors that affect physical and mental performance $(1,2)$. Evidence suggest that global population of older people will be more than1.4 billion by 2030 (3-5). In addition, diseases that have neurological roots, such as Alzheimer's and memory disorders, appear to be on the rise, so all countries should be aware of the costs of these disorders occurring in the elderly (6). To address this global challenge, much research has been conducted around the world to study the mechanisms associated with cognitive impairment and brain aging in the elderly (7). The Cognitive processes include learning, attention, memory, language, reasoning, and decision making which are all possibly affected by aging process $(8,9)$. Evidence shows that cognitive processes decline from adulthood to old ages $(10,11)$. These degenerative changes usually begin in the third decade of life and affect the cognitive function of individuals (11). Normal cognitive processes are clearly present in two stages of life. One stage is from puberty to adulthood, which occurs automatically, and the second stage is from adulthood to old age, which requires environmental issues affecting cognitive function to be considered (10-12). There are some evidences suggesting that micronutrients such as vitamins, antioxidants, and B vitamins play a role in nerve protection. For example, vitamin B12 is an essential micronutrient found only in foods of animal origin and is necessary for healthy nerve tissue and brain function (13). Vitamin A also regulates most nerve growth pathways that can reasonably affect cognition (14). Nutrient deficiencies is not only associated with body composition and physical fitness (muscle atrophy, etc.), but also affects the brain health leading to cognitive disturbances in the elderly (15). The recommended micronutrients in diet for the elderly in France is as follows: daily intake of 15 to $10 \mathrm{mg}$ of zinc, $80 \mathrm{mg}$ of selenium, 15 to $50 \mathrm{mg}$ of vitamin E, $120 \mathrm{mg}$ of vitamin C and $400 \mathrm{mg}$ of folate. An insufficient intake of theses micronutrients in older people has been reported in several studies $(16,17)$. There are other factors that can affect the cognitive function of the elderly (e.g., Smell and taste disorders, as well as tooth decay and digestive disorders) (18). In addition, environmental problems (loneliness, economic conditions, de- 
pression, substance abuse) may reduce essential nutrient intake leading to clinical side effects and vitamin deficiencies (19). Hence, it is important to follow a diet plan for people over the age of 50. For example, diets recommended for the treatment of obesity, dyslipidemia, osteoporosis or constipation may lead to changes in the intake and absorption of micronutrients (20). It was found in a study that 8.3\% of Korean aged people 65 had cognitive impairment. At the same time, it was reported that they often had problems with micronutrient intake (21). As noted, aged persons are at risk for low energy and protein intake and deficiency of some micronutrients such as vitamin C, vitamin B12, vitamin A, folate and zinc (22). Studies show that the world's population is rapidly growing over the world and this process is increasing in developing countries at the beginning of the 21st century. This is also the case in our country. On the other hand, responsibility for families where the elderly live is another cost to the family and society, so it is necessary to adopt strategies that prevent cognitive impairment (23). reported that physical activity is an effective strategy in preventing and the progression of Alzheimer's disease. It has also been reported that aerobic exercise and yoga affect the memory and dynamic balance of elderly men (24). Research results showed that physical activity has a significant effect on improvement of memory in aged female (25). exercise can improve cognitive function by improving cerebral blood flow, increasing hippocampal volume, and improving neurogenesis (26). The obtained results in this study can be useful for all those who are in contact with the elderly. On the other hand, there is a research gap regarding the consumption of micronutrients and motor and cognitive function of the elderly.

\section{Objectives}

The purpose of this study was to investigate the effect of micronutrient intake on cognitive function and physical activity of the elderly.

\section{Methods}

\subsection{Participants}

The subjects included all elderly people over 60 years of age in Robat Karim city in 2018. Ninety elderly males participated voluntarily in the research after signing the informed consent form. The first call for research was made through social networks as well as relevant organizations, and finally ninety elderly people announced their readiness to participate in this research, and 70 of them who met the eligibility criteria were included in the study. Inclusion criteria were age over 65 , ability to answer questions, alertness, no history of falls in the last 6 months, no memory or forgetfulness disorders, and having functional independence such as walking.

\subsection{Measurement}

The short form of Beck questionnaire of physical activity and MMSE test were used respectively to measure the levels of physical activity and cognitive status of aged individuals.

Before carrying out the work, all stages of their research were explained. The MMSE consists of seven domains, each with an assigned point value totaling 30: (1) orientation to time (5 points); (2) orientation to place (5 points); (3) three word registration (3 points); (4) attention and calculation (5 points); (5) three word recall (3 points); (6) language (8 points); and (7) visual construction (pentagon copying, 1 point). An MMSE score greater or equal to 24 were considered normal cognitive function, while scores less than 24 indicated cognitive impairment. The reliability of MMSE has been reported to be $79 \%$.

\subsection{Procedure}

The common dietary intakes of participants over the past year were assessed using a valid food frequency questionnaire consisting of 168 food items. The amount of micronutrients and energy intake of each person was calculated via N4 software. A short version of the questionnaire of Beck (27) was used to measure the amount of physical activity. It includes 16 questions in three components of workplace, leisure time and sports (see equation 1). Questions 1 to 8 refers to physical activity at work and questions 9 to 16 are related to exercise in leisure time and home. The reliability of this questionnaire was calculated to be 0.79 (28). Calculation of physical activity level is as follow:

Labor Index : $\left[\frac{I_{1}+\left(6-I_{2}\right)+13+8}{I_{4}+I_{5}+I_{6}+I_{7}+I_{8}}\right]$

Sport Index $: \frac{19+I_{10}+I_{11}+I_{12}}{4}$

leisure Time Index $: \frac{\left(6-I_{13}\right)+I_{14}+I_{15}+I_{16}}{4}$

Total Index : LabarIndex + Sport Index + Leisure Time Index

\subsection{Statistical Analysis}

Pearson correlation test was used to analyze the data using the SPSS v21.0 software (SPSS Inc., Chicago, IL). Data were presented as mean $\pm S D$ in the table and the text. 


\begin{tabular}{|c|c|}
\hline Demographic Characteristic & Mean $\pm \mathbf{S D}$ \\
\hline Age & $68.8 \pm 5.3$ \\
\hline Weight (kg) & $75.9 \pm 10.9$ \\
\hline Height $(\mathbf{m})$ & $1.70 \pm 0.3$ \\
\hline \multicolumn{2}{|l|}{ Table 2. Research Variables } \\
\hline Variables & Mean \pm SD \\
\hline Cognitive function & $23.3 \pm 4.58$ \\
\hline Physical activity & $2.25 \pm 1.34$ \\
\hline \multicolumn{2}{|l|}{ Micronutrients (mg) } \\
\hline EPA & Very little \\
\hline Iron & $15.55 \pm 18.34$ \\
\hline Sodium & $12456.16 \pm 1029.48$ \\
\hline Manganese & $2.45 \pm 1.44$ \\
\hline Zinc & $9.78 \pm 128.19$ \\
\hline Magnesium & $2.44 \pm 3.35$ \\
\hline Iodine & $6.85 \pm 1.52$ \\
\hline Vitamin A & $729.29 \pm 11.75$ \\
\hline Vitamin E & $30.64 \pm 13724.62$ \\
\hline Thiamine & $1.4 \pm 0.5$ \\
\hline Niacin & $19.65 \pm 11.15$ \\
\hline Folate & $298.49 \pm 327.42$ \\
\hline Pantothenic acid & $3.45 \pm 1.59$ \\
\hline Vitamin C & $169.53 \pm 12.74$ \\
\hline Vitamin K & $79.95 \pm 201.33$ \\
\hline Cholesterol & $182.75 \pm 125.49$ \\
\hline DHA & Very little \\
\hline Calcium (mg/d) & $729.15 \pm 498.34$ \\
\hline Potassium & $2987.98 \pm 1725.09$ \\
\hline Phosphorus & $1986.44 \pm 982.44$ \\
\hline$\beta$-carotene & $1542.48 \pm 4236.24$ \\
\hline$\alpha$-tocopherol & $6.24 \pm 15.32$ \\
\hline Riboflavin & $1.56 \pm 0.68$ \\
\hline Pyridoxine & $1.55 \pm 0.66$ \\
\hline Cobalamin & $6.68 \pm 15.42$ \\
\hline Biotin & $10.77 \pm 7.65$ \\
\hline Vitamin D & $0.68 \pm 1.01$ \\
\hline
\end{tabular}

\section{Results}

General information and descriptive variables of the research are reported in Tables 1 and 2.

As seen in Table 3, Shapiro Wilk test was used to check the normality of data distribution. The test results show that the data distribution was normal.

\begin{tabular}{|c|c|c|}
\hline \multirow{2}{*}{ Variables } & \multicolumn{2}{|c|}{ Shapiro-Wilk } \\
\hline & $\mathbf{Z}$ & $\mathbf{P}$ \\
\hline Cognitive function & 0.842 & 0.312 \\
\hline Physical activity & 0.645 & 0.315 \\
\hline $\operatorname{EPA}(\mathbf{m g})$ & 0.742 & 0.641 \\
\hline Iron (mg) & 0.771 & 0.316 \\
\hline Sodium (mg) & 0.312 & 0.841 \\
\hline Manganese (mg) & 0.735 & 0.153 \\
\hline Zinc (mg) & 0.678 & 0.398 \\
\hline Magnesium (mg) & 0.835 & 0.088 \\
\hline Iodine (mg) & 0.543 & 0.648 \\
\hline Vitamin A (mg) & 0.902 & 0.314 \\
\hline Vitamin E (mg) & 0.443 & 0.658 \\
\hline Thiamine (mg) & 0.523 & 0.148 \\
\hline Niacin (mg) & 0.779 & 0.348 \\
\hline Folate (mg) & 0.684 & 0.648 \\
\hline $\begin{array}{l}\text { Pantothenic acid } \\
\text { (mg) }\end{array}$ & 0.463 & 0.348 \\
\hline Vitamin C (mg) & 0.341 & 0.487 \\
\hline Vitamin K (mg) & 0.503 & 0.187 \\
\hline Cholesterol (mg) & 0.901 & 0.981 \\
\hline DHA (mg) & 0.664 & 0.476 \\
\hline Calcium (mg/d) & 0.387 & 0.682 \\
\hline Potassium (mg) & 0.663 & 0.079 \\
\hline Phosphorus (mg) & 0.778 & 0.641 \\
\hline$\beta$-carotene $(\mathbf{m g})$ & 0.870 & 0.099 \\
\hline$\alpha$-tocopherol (mg) & 0.992 & 0.248 \\
\hline Riboflavin (mg) & 0.416 & 0.516 \\
\hline Pyridoxine (mg) & 0.648 & 0.551 \\
\hline Cobalamin (mg) & 0.764 & 0.271 \\
\hline Biotin (mg) & 0.441 & 0.334 \\
\hline Vitamin D (mg) & 0.310 & 0.684 \\
\hline
\end{tabular}

According to Table 4, the results of Pearson correlation test showed that there was a significant relationship between each of the micronutrients with cognitive function in the elderly ( $\mathrm{P} \geq 0.05)$.

As shown in Table 5, the results of Pearson correlation test showed that there was a significant relationship between each of the micronutrients with motor function in the elderly ( $\mathrm{P} \geq 0.05)$. 


\begin{tabular}{|c|c|c|}
\hline \multirow{2}{*}{$\begin{array}{l}\text { Variables } \\
\text { (Micronutrients) }\end{array}$} & \multicolumn{2}{|c|}{ Cognitive Function } \\
\hline & $\mathbf{R}$ & $\mathbf{P}$ \\
\hline Iron (mg) & 0.551 & 0.001 \\
\hline Sodium (mg) & 0.208 & 0.024 \\
\hline Manganese (mg) & 0.654 & 0.001 \\
\hline Zinc (mg) & 0.532 & 0.001 \\
\hline Magnesium (mg) & 0.622 & 0.001 \\
\hline Iodine (mg) & 0.395 & 0.018 \\
\hline Vitamin A (mg) & 0.648 & 0.001 \\
\hline Vitamin E (mg) & 0.335 & 0.001 \\
\hline Thiamine (mg) & 0.415 & 0.016 \\
\hline Niacin (mg) & 0.553 & 0.001 \\
\hline Folate (mg) & 0.598 & 0.001 \\
\hline $\begin{array}{l}\text { Pantothenic acid } \\
\text { (mg) }\end{array}$ & 0.328 & 0.025 \\
\hline Vitamin C (mg) & 0.234 & 0.045 \\
\hline Vitamin K (mg) & 0.415 & 0.012 \\
\hline Cholesterol (mg) & 0.637 & 0.001 \\
\hline Calcium (mg/d) & 0.263 & 0.024 \\
\hline Potassium (mg) & 0.248 & 0.011 \\
\hline Phosphorus (mg) & 0.325 & 0.028 \\
\hline$\beta$-carotene $(\mathrm{mg})$ & 0.601 & 0.001 \\
\hline$\alpha$-tocopherol (mg) & 0.622 & 0.001 \\
\hline Riboflavin (mg) & 0.334 & 0.028 \\
\hline Pyridoxine (mg) & 0.429 & 0.001 \\
\hline Cobalamin (mg) & 0.550 & 0.001 \\
\hline Biotin (mg) & 0.325 & 0.034 \\
\hline Vitamin D (mg) & 0.228 & 0.041 \\
\hline
\end{tabular}

\section{Discussion}

As shown in result section, a significant relationship was found between each of the micronutrients with cognitive function in the elderly. This result is consistent with the results of GU (29) and Gustaw-Rothenberg (30). They stated that a healthy diet pattern that is positively correlated with the consumption of fruits (fresh and dried), whole grains, Fresh dairy products, vegetables, breakfast cereals, tea, vegetable fats, nuts and fish, and inversely related to consumption of red meat and poultry, refined grains, animal fats and processed meats (31).

On the other hand, the obtained results aren't consistent with the results of $(21,32)$. In another study, protein intake was higher in active people than in people with lower levels of physical activity (33). There are sev-

\begin{tabular}{|c|c|c|}
\hline \multirow{2}{*}{$\begin{array}{l}\text { Variables } \\
\text { (Micronutrients) }\end{array}$} & \multicolumn{2}{|c|}{ Motor Function } \\
\hline & $\mathbf{R}$ & Sig. \\
\hline Iron (mg) & 0.445 & 0.001 \\
\hline Sodium (mg) & 0.625 & 0.001 \\
\hline Manganese (mg) & 0.458 & 0.001 \\
\hline Zinc (mg) & 0.553 & 0.001 \\
\hline Magnesium (mg) & 0.601 & 0.001 \\
\hline Iodine (mg) & 0.435 & 0.001 \\
\hline Vitamin A(mg) & 0.556 & 0.015 \\
\hline Vitamin E (mg) & 0.412 & 0.001 \\
\hline Thiamine (mg) & 0.556 & 0.001 \\
\hline Niacin (mg) & 0.326 & 0.024 \\
\hline Folate (mg) & 0.601 & 0.001 \\
\hline $\begin{array}{l}\text { Pantothenic acid } \\
\text { (mg) }\end{array}$ & 0.446 & 0.001 \\
\hline Vitamin C (mg) & 0.401 & 0.022 \\
\hline Vitamin K (mg) & 0.558 & 0.001 \\
\hline Cholesterol(mg) & 0.789 & 0.001 \\
\hline Calcium (mg/d) & 0.635 & 0.001 \\
\hline Potassium (mg) & 0.432 & 0.001 \\
\hline Phosphorus (mg) & 0.226 & 0.033 \\
\hline$\beta$-carotene $(\mathbf{m g})$ & 0.712 & 0.001 \\
\hline$\alpha$-tocopherol (mg) & 0.552 & 0.001 \\
\hline Riboflavin (mg) & 0.618 & 0.001 \\
\hline Pyridoxine (mg) & 0.213 & 0.042 \\
\hline Cobalamin (mg) & 0.569 & 0.001 \\
\hline Biotin (mg) & 0.378 & 0.004 \\
\hline Vitamin D (mg) & 0.369 & 0.009 \\
\hline
\end{tabular}

eral facts suggesting beneficial effects of polyunsaturated fatty acids (PUFAs) fats such as fish and MUFA fatty acids. Another study found that omega-3 fatty acids are beneficial for brain health through their anti-inflammatory, antioxidant and antithrombotic properties (34). Vitamin B12 and folate can affect Alzheimer's disease by lowering circulating homocysteine levels. Since, the elderly is at risk for low energy and protein intake and deficiency of some micronutrients, it's necessary to consider some interventions such as training and prescribing nutritional supplements. It was also observed in a study that there was a positive and significant relationship between calorie intake and dietary pattern indicators and micronutrient intake with sedentary behaviors (32). Evidence has shown that tooth decay and musculoskeletal disorders reduce self-esteem in the elderly and ultimately reduce their presence in physical ac- 
tivity, and this is one of the issues that can directly affect their cognitive function (18). However, the relationship between motor function and cognitive function in lower age groups such as adolescence has not always been positive (21). For example, a study found that there is no significant relationship between physical and cognitive function in adolescents. It seems that the differences in the findings of the present study with other studies would be related to differences in lifestyle, socio-economic and cultural status. In general, the results showed that there is a significant relationship between each of the micronutrients with the cognitive function of the elderly. On the other hand, the results showed that there is a significant relationship between each of the elements of micronutrients with the motor function of the elderly. There are several limitations in the study, including low number of participants, different levels of economic status and education. The lack of precise control of the participants' motivation to answer the research questions was another limitation of this research, so, it is suggested to study more samples to study with more certainty.

\section{Footnotes}

Authors' Contribution: A.A developed the original idea and the protocol, abstracted and analyzed data, wrote the manuscript, and is a guarantor. M.A, S.T and F.M contributed to the development of the protocol, abstracted data, and prepared the manuscript.

Conflict of Interests: There is no conflict of interest.

Ethical Approval: Approved by the University Research Committee

Funding/Support: This research received no external funding.

Informed Consent: Ninety elderly males participated voluntarily in the research after signing the informed consent form.

\section{References}

1. Irandoost K, Taheri M, Seghatoleslami A. [The effects of weight loss by physical activity and diet on depression levels of highly depressed elderly females]. Iran J Ageing. 2015;10(1):48-53. Persian.

2. Bales CW, Ritchie CS. Sarcopenia, weight loss, and nutritional frailty in the elderly. Annu Rev Nutr. 2002;22:309-23. doi: 10.1146/annurev.nutr.22.010402.102715. [PubMed: 12055348].

3. Taheri M, Irandoust $\mathrm{K}$. The effect of balance exercises and computerized cognitive training on psychomotor performance in elderly. $J$ Phys Ther Sci. 2017;29(12):2097-9. doi: 10.1589/jpts.29.2097. [PubMed: 29643582]. [PubMed Central: PMC5890208].

4. Seghatoleslami A, Hemmati Afif A, Irandoust K, Taheri M. [Effect of Pilates Exercises on Motor Performance and Low Back Pain in Elderly Women With Abdominal Obesity]. Iran J Ageing. 2018;13(3):396-405. Persian. doi: 10.32598/sija.13.3.396.
5. Taheri M, Irani K. The effect of water-based exercise programs and KSD protocol on general health questionnaire and optimal physical fitness factors affecting female elders balance.J Mot Behav. 2014;6(16):1528.

6. Alzheimer's A. 2015 Alzheimer's disease facts and figures. Alzheimers Dement. 2015;11(3):332-84. doi: 10.1016/j.jalz.2015.02.003. [PubMed: 25984581].

7. Miquel S, Champ C, Day J, Aarts E, Bahr BA, Bakker M, et al. Poor cognitive ageing: Vulnerabilities, mechanisms and the impact of nutritional interventions. Ageing Res Rev. 2018;42:40-55. doi: 10.1016/j.arr.2017.12.004. [PubMed: 29248758].

8. Monti JM, Moulton CJ, Cohen NJ. The role of nutrition on cognition and brain health in ageing: a targeted approach. Nutr Res Rev. 2015;28(2):167-80. doi: 10.1017/S0954422415000141. [PubMed: 26650244].

9. Naghavi N, Taheri M, Irandoust K. Psychophysiological Responses to Cognitive and Physical Training in Obese Elderly. Int J Sport Stud Hlth. 2018;1(3). e83935. doi: 10.5812/intjssh.83935.

10. Salthouse T. Consequences of age-related cognitive declines. Annu Rev Psychol. 2012;63:201-26. doi: 10.1146/annurev-psych-120710-100328. [PubMed: 21740223]. [PubMed Central: PMC3632788].

11. Salthouse TA. Selective review of cognitive aging. J Int Neuropsychol Soc. 2010;16(5):754-60. doi: 10.1017/S1355617710000706. [PubMed: 20673381]. [PubMed Central: PMC3637655].

12. Irandoust K, Taheri M, Mirmoezzi M, H'Mida C, Chtourou H, Trabelsi $\mathrm{K}$, et al. The Effect of Aquatic Exercise on Postural Mobility of Healthy Older Adults with Endomorphic Somatotype. Int J Environ Res Public Health. 2019;16(22). doi: 10.3390/ijerph16224387. [PubMed: 31717625]. [PubMed Central: PMC6888232].

13. Rathod R, Kale A, Joshi S. Novel insights into the effect of vitamin $\mathrm{B}(1)(2)$ and omega-3 fatty acids on brain function. J Biomed Sci. 2016;23:17. doi: 10.1186/s12929-016-0241-8. [PubMed: 26809263]. [PubMed Central: PMC4727338].

14. Ali H, Hamadani J, Mehra S, Tofail F, Hasan MI, Shaikh S, et al. Effect of maternal antenatal and newborn supplementation with vitamin A on cognitive development of school-aged children in rural Bangladesh: a follow-up of a placebo-controlled, randomized trial. Am J Clin Nutr. 2017;106(1):77-87. doi: 10.3945/ajcn.116.134478. [PubMed: 28490513].

15. Ferry M, Roussel AM. Micronutrient status and cognitive decline in ageing. Eur Geriatr Med.2011;2(1):15-21. doi:10.1016/j.eurger.2010.11.014.

16. De Groot LCPGM, van Staveren WA, Hautvast JGAJ. Euronut-Seneca: Nutrition and the elderly in Europe. 1st European Congress on Nutrition and Health in the Elderly. Eur J Clin Nutr. 1991;45(Suppl 3):1-196. [PubMed: 1687315].

17. Taheri M, Irandost K, Mirmoezzi M, Ramshini M. Effect of Aerobic Exercise and Omega-3 Supplementation on psychological aspects and Sleep Quality in Prediabetes Elderly Women. Sleep and Hypnosis. 2018;21(2):170-4. doi: 10.5350/Sleep.Hypn.2019.21.0185.

18. Gariballa S. Nutrition and older people: special considerations relating to nutrition and ageing. Clin Med (Lond). 2004;4(5):411-4. doi: 10.7861/clinmedicine.4-5-411. [PubMed: 15536868]. [PubMed Central: PMC5351895].

19. Ferry M, Sidobre B, Lambertin A, Barberger-Gateau P. The SOLINUT study: analysis of the interaction between nutrition and loneliness in persons aged over 70 years. J Nutr Health Aging. 2005;9(4):261-8. [PubMed: 15980927].

20. Gillette Guyonnet S, Abellan Van Kan G, Andrieu S, Barberger Gateau $\mathrm{P}$, Berr C, Bonnefoy M, et al. IANA task force on nutrition and cognitive decline with aging. J Nutr Health Aging. 2007;11(2):132-52. [PubMed: 17435956].

21. Kim CO, Lee KR. Preventive effect of protein-energy supplementation on the functional decline of frail older adults with low socioeconomic status: a community-based randomized controlled study. J Gerontol A Biol Sci Med Sci. 2013;68(3):309-16. doi: 10.1093/gerona/gls167. [PubMed: 22879453]. 
22. Morley JE. Undernutrition in older adults. Fam Pract. 2012;29(Suppl 1):i89-93. doi: 10.1093/fampra/cmr054. [PubMed: 22399563].

23. Petry H, Ernst J, Steinbruchel-Boesch C, Altherr J, Naef R. The acute care experience of older persons with cognitive impairment and their families: A qualitative study. Int J Nurs Stud. 2019;96:44-52. doi: 10.1016/j.ijnurstu.2018.11.008. [PubMed:30660445].

24. Irandoust K, Taheri M. [The Impact of Yoga and Pilates Exercises on Older Adults]. Iran J Ageing. 2016;11(1):152-61. Persian. doi: 10.21859/sija1101152.

25. Sadeghi N, Khalaji H, Noroozian M, Mokhtari P. [Effects of physical activity on the memory in 50-70 year-old-women with mild cognitive impairment]. New Cellular \& Molecular Biotechnology Journal. 2013;3(11):47-54. Persian.

26. Sinaei M, Nazem F, Alaei H, Talebi A. [The role of aerobic exercise training patterns on learning function and memory performance: A review article]. KAUMS Journal (FEYZ). 2019;23(5):563-77. Persian.

27. Beck AT, Steer RA. Relationship between the beck anxiety inventory and the Hamilton anxiety rating scale with anxious outpatients. JAnxiety Disord. 1991;5(3):213-23. doi:10.1016/0887-6185(91)90002-b.

28. Rafighi L, Zamani Sani SH, Bashiri M, Fathirezaie Z. Assessing the Relationship between Physical Activity and Life Satisfaction among Women: Path Analysis Model.Journal of Health Promotion Managment. 2017;6(4):50-8. doi: 10.21859/jhpm-06048.

29. Gu Y, Nieves JW, Stern Y, Luchsinger JA, Scarmeas N. Food combination and Alzheimer disease risk: a protective diet. Arch Neu- rol. 2010;67(6):699-706. doi: 10.1001/archneurol.2010.84. [PubMed: 20385883]. [PubMed Central: PMC3029147].

30. Gustaw-Rothenberg K. Dietary patterns associated with Alzheimer's disease: population based study. Int J Environ Res Public Health. 2009;6(4):1335-40. doi: 10.3390/ijerph6041335. [PubMed: 19440521]. [PubMed Central: PMC2681193].

31. Kesse-Guyot E, Andreeva VA, Jeandel C, Ferry M, Hercberg S, Galan P. A healthy dietary pattern at midlife is associated with subsequent cognitive performance. J Nutr. 2012;142(5):909-15. doi: 10.3945/jn.111.156257. [PubMed: 22457391].

32. Lake AA, Townshend T, Alvanides S, Stamp E, Adamson AJ. Diet, physical activity, sedentary behaviour and perceptions of the environment in young adults. J Hum Nutr Diet. 2009;22(5):444-54. doi: 10.1111/j.1365277X.2009.00982.x. [PubMed: 19743982].

33. Kelishadi R, Ardalan G, Gheiratmand R, Gouya MM, Razaghi EM, Delavari A, et al. Association of physical activity and dietary behaviours in relation to the body mass index in a national sample of Iranian children and adolescents: CASPIAN Study. Bull World Health Organ. 2007;85(1):19-26. doi: 10.2471/blt.06.030783. [PubMed: 17242754]. [PubMed Central: PMC2636217].

34. Swanson D, Block R, Mousa SA. Omega-3 fatty acids EPA and DHA: health benefits throughout life. Adv Nutr. 2012;3(1):1-7. doi: 10.3945/an.111.000893. [PubMed: 22332096]. [PubMed Central: PMC3262608]. 